\title{
Harmonia e música dionisíaca: do Drama musical grego ao Nascimento da tragédia*
}

\author{
Christophe Corbier**
}

\begin{abstract}
Resumo: O presente artigo tenta mostrar que as teses estéticas que aparecem em $O$ nascimento da tragédia não são resultado de uma mera projeção subjetiva de Nietzsche sobre a arte grega. Isso porque, subjacente à argumentação de $O$ nascimento da tragédia, haveria uma vasta fundamentação historiográfica cujos traços podem ser encontrados nos textos filológicos que antecedem a primeira obra filosófica de Nietzsche. Tendo isso em mente, este artigo vai realizar uma investigação nos textos em questão para tentar provar que a crítica de "projeção subjetiva" não se sustenta. Durante o exame, o tentaremos evidenciar, por exemplo, que a compreensão de Nietzsche acerca da ligação entre o aparecimento histórico da harmonia e o dionisismo grego está intimamente ligada às posições que aprecem em seus estudos filológicos dos anos 1860-1871. Posições que são derivadas e estariam legitimadas por dados da pesquisa historiográfica do século XIX.
\end{abstract}

Palavras-chaves: $O$ nascimento da tragédia- dionisíaco - harmonia música - melodia - cultura grega

"Why music?" Em Nietzsche on tragedy, Michael Stephen Silk e Joseph Peter Stern, manifestaram seu ceticismo frente à evocação da música grega antiga em $O$ nascimento da tragédia: que relação tal arte pode ter com Tristão e Isolda, o modelo reivindicado por Nietzsche? Como Nietzsche, sem dúvida cegado por seu amor à música, não pôde notar a diferença de natureza entre esses dois

\footnotetext{
* Tradução de João Evangelista Tude de Melo Neto.

** Pesquisador do CNRS-CRAL-EHESS, França. Endereço eletrônico: christophecorbier@ club-internet.fr.
} 
sistemas musicais? ${ }^{1}$. As críticas de Silk e Sterne visam em particular o segundo capítulo: num longo parágrafo, Nietzsche opõe a citaródia apolínea, "arquitetura de sons", à aulodia dionisíaca, caracterizada pelo som musical, pelo melos e pela harmonia (cf. GT/NT 2, KSA 1.31-34). Esse último termo, entretanto, parece problemático: hoje em dia é impossível sustentar que os gregos tenham conhecido a harmonia no sentido clássico do termo, isto é, o emprego de acordes de três ou quatro sons organizados segundo uma hierarquia funcional tirada dos harmônicos de um corpo sonoro. Silk e Sterne consideram que Nietzsche não foi intelectualmente honesto ao ignorar a verdadeira natureza da música grega, monódica e modal ${ }^{2}$. De maneira similar, Jochen Schmidt taxou essa passagem de "ahistorisches Phantasie"3; quanto a Barbara von Reibnitz, que analisou as fontes do filólogo, ela estima que Nietzsche, perfeitamente consciente da diferença entre a música grega e a música moderna, jogou com a ambiguidade das palavras para anular a historicidade da música grega ${ }^{4}$.

Como é possível imaginar, contudo, que o discípulo Ritschl tenha podido ignorar todos esses fatos quando ele redigia $\mathrm{O} \mathrm{Nas-}$ cimento da tragédia? ${ }^{5}$. Desde 18 de fevereiro de 1870, ele declara publicamente que "a música coral em uníssono (die unisone Chormusik) dos gregos [...] constitui um contraste (Gegensatz)

1 SILK, S.; STERN, J. P. Nietzsche on tragedy. Cambridge: Cambridge University Press, 1981, p. $246-247$.

2 Ibid. p, 138. Nas páginas 137-141, Silk e Sterne listam os "erros" de Nietzsche.

3 SCHMIDT, J. Nietzsche-Kommentar. Die Geburt der Tragödie, Berlin-New-York: De Gruyter, 2012 , p. 132. Georges Liébert lembrou que, a não ser que, como Nietzsche, cometa-se um grosseiro contrassenso, harmonia e harmonia grega são distintas (LIÉBERT, G. Nietzsche et la musique, Paris: PUF-Quadrige, 1995, p. 56).

4 REIBNITZ, B. Ein Kommentar zu Friedrich Nietzsche, "Die Geburt der Tragödie aus dem Geiste der Musik»(Kap. 1-12), Weimar: Verlag J. B. Metzler Stuttgart, 1992, p. 118-119.

5 Notemos que Friederike Felicitas Günther sublinhou recentemente que Nietzsche não ignorava o caráter monódico da música grega e que ele indicou, em 1874, no seu curso sobre a história da literatura grega, que os gregos não praticavam a harmonia simultânea à maneira moderna (GÜNTHER, F. F. Rhythmus beim frühen Nietzsche. Berlin: De Gruyter, 2008. p, 74). Podemos também nos reportar às explicações, um pouco embaraçosas, de Eric Dufour sobre a relação entre melodia e harmonia na Grécia em $O$ nascimento da tragédia (DUFOUR, E. L'esthétique musicale de Nietzsche. Lille: Presses du Septentrion. 2005, p. 94-95). 
extremo com a evolução musical cristã, na qual a harmonia, o verdadeiro símbolo da multiplicidade, dominou tanto tempo que a melodia ficou sufocada e teve de ser redescoberta" (GMD/DM, KSA 1.526). Seguramente, no estado atual de nossos conhecimentos musicológicos, uma contradição surge desde o momento que se quer assimilar a música grega a partir da música moderna. Mas a interpretação da noção de "harmonia" na Grécia e sua ligação com a música dionisíaca consite numa distorção quando é vista apenas do ponto de vista estético, sem referência aos dados históricos sobre os quais Nietzsche se apoia constantemente de maneira implícita - dados que podem ser encontrados em abundância nas suas aulas sobre os poetas gregos líricos (1869), sobre as Coéforas (1870), sobre a rítmica grega (1870) e sobre Édipo Rei (1870). Ora, além de ser compositor (sem querer julgar o valor de suas obras musicais), Nietzsche era um dos jovens filólogos mais hábeis de seu tempo no que concerne à poesia e à música grega. Levando isso em conta, nós devemos, portanto, tentar entender porque ele foi capaz de associar as noções de "dionisíaco" e de "harmonia" de forma legítima.

Para elucidar essa questão, vamos tentar refazer o caminho que Nietzsche percorreu. Caminho que foi da história da música em direção à metafísica e à estética, sem que nunca o filósofo-filólogo tenha quebrado a ligação entre essas disciplinas - ao contrário de seus antecessores Hanslick e Schopenhauer, críticos de Hegel e da ciência histórica. Nesse sentido, é através das ferramentas e das categorias historiográficas da segunda metade do século XIX que é preciso analisar o segundo capítulo de $O$ nascimento da tragédia: longe de ser uma projeção de Nietzsche sobre a arte grega, a ligação que é feita entre do aparecimento histórico da harmonia e o dionisismo pode ser justificada pelas obras científicas dos anos 1860-1870, nas quais essa associação era invocada com base nos textos gregos. Que, hoje, essa tese tenha sido invalidada, não significa, contudo, que ela tenha sido considerada ilegítima para os helenistas do final do século XIX. 
Portanto, o problema se apresentou a Nietzsche tanto como uma questão de história da música como também de estética e metafísica. O jovem filólogo abordou a questão da harmonia na Grécia desde sua primeira conferência "preparatória" sobre o Drama musical grego: o objetivo era de contestar Hanslick no terreno da filologia para responder aos ataques que este desferiu contra a música grega. Em seguida, a reflexão de Nietzsche se enriqueceu de elementos wagnerianos para depois encontrar sua forma definitiva em $O$ nascimento da tragédia. Lendo as linhas do capítulo II de maneira filológica e, assim, privilegiando a leitura lenta e cuidadosa da palavra que o próprio filósofo recomenda no prefácio de Aurora (1886), nós poderemos realizar uma interpretação histórica e filosófica da relação estabelecida entre a harmonia e a música dionisíaca em $O$ nascimento da tragédia.

Nietzsche contra Hanslick: a música grega entre estética e filologia

Antes de endereçar críticas irônicas em $O$ nascimento da tragédia a Eduard Hanslick e a Otto Jahn, incapazes de conceber a música segundo a categoria do sublime ${ }^{6}$, Nietzsche contestou o esteta em janeiro de 1870 em sua conferência sobre o drama musical grego. Sabe-se que Nietzsche, já em 1865, havia lido Du Beau musical em sua terceira edição e que antes de criticar as posições de Hanslick no fim dos anos 1870 ele havia relido seu livro por volta de 1870-1871. E esse era justamente o momento em que ele concebia $O$ nascimento da tragédia ${ }^{7}$. O Drama musical grego atesta

6 GT/NT 19, KSA 1.127-128. Nietzsche associa Hanslick a Jahn em Nachlass/FP 1871, 9 [8], KSA 7.273.

7 LANDERER, C.; SCHUSTER, M. Nietzsches Vorstudien zur Geburt der Tragödie in ihrer Beziehung zur Musikästhetik Eduard Hanslicks“, Nietzsche Studien, 31, 2002, p. 119-120. Cf. GÜNTHER, F. F. Rhythmus beim frühen Nietzsche, op. cit., p, 74-81. Sobre a relação entre a estética de Hanslick e a concepção da música em Humano demasiado humano, Cf. DUFOUR, E. L'esthétique musicale de Nietzsche. op. cit. p. 181-211.

66 I Cad. Nietzsche, São Paulo, n. 34 - vol. I, p. 61-98, 2014. 
indiscutivelmente esse dado: o jovem professor extraordinário de filologia clássica, amigo íntimo de Wagner, afronta o poderoso crítico musical que, nomeado doctor honoris causa da Universidade de Viena en 1870, ocupava oficialmente nessa instituição a cátedra de história e estética da música. No âmago da polêmica levantada por Nietzsche em sua conferência reside o problema do valor da música grega antiga. Ora, sua avaliação depende, desde o fim do século XVII, de um aspecto central: o uso da harmonia. Longe de ser solucionada com a Querela dos Antigos e Modernos, o debate prosseguiu ao longo do século XIX ${ }^{8}$. Desde 1854, em Vom Musikalisch-Schönen, Hanslick aborda, por sua vez, o problema da harmonia na Grécia para responder a Wagner, que reivindicava a tragédia musical como o gênero precursor do drama lírico.

É conforme seu próprio sistema que Hanslick se propõe a julgar a música grega: para ele, a música não é uma língua nascida da expressão das paixões; ela não manifesta os sentimentos do músico conforme um código retórico que pega de empréstimo da arte poética. A música, se ela de fato consiste numa linguagem, é intraduzível em conceitos. Quanto ao belo musical, este se trata de uma qualidade objetiva, independentemente das circunstâncias históricas. De tal forma que o pertencimento a uma escola ou a uma nação constitui algo secundário. $\mathrm{O}$ belo musical se caracteriza pela união de partes que se desdobram harmoniosamente, à maneira de um arabesco, numa obra pura, absoluta, livre da palavra. Hanslick distingue, em seguida, dois tipos de escuta: a compreensão "estética" e a compreensão "patológica". Apenas a compreensão "estética" é adequada para desfrutar plenamente da obra musical. Essa escuta, fundada na intuição e na reflexão, está adaptada ao trabalho do

8 Desde as críticas de Charles Perrault contra a musique antiga, considerada como uma melodia rudimentar em relação à harmonia moderna no quarto volume do Parallèle entre les Anciens et les Modernes (1697), até o conflito entre Rameau e Rousseau nos anos 1750, a questão da harmonia grega, implicando a tese da perfeição ou da imperfeição da música antiga, foi longamente discutida. Sobre esse tema sugerimos nossa obra CORBIER, C. Poésie, musique et danse. Maurice Emmanuel et l'hellénisme. Paris: Classiques Garnier. 2010, p. 44-60. 
compositor que não se deixa jamais conduzir ao entusiasmo nem à efusão subjetiva. A embriaguez, a compreensão "patológica" da música, consiste numa escuta elementar, passiva, fundada na excitação nervosa e no prazer dos sentidos e que age de forma indistinta sobre os animais e sobre os homens.

É no contexto dessa oposição entre as duas formas de escuta que Hanslick se volta contra a música grega. Célebres anedotas que mostram Aquiles acalmando sua dor com a lira (Ilíada, I, 472 sq.), Taletas apaziguando uma guerra civil através de sua arte (Plutarco, Licurgo, 4) ou Pitágoras acalmando um jovem homem embriagado por meio de alguns "modos" específicos (Boécio, De Institutione Musica, I, 1) fornecem recorrentemente exempla destinados a mostrar o poder da música grega. Contudo, para Hanslick, esses exemplos provam, ao contrário, que os gregos não haviam ainda atingido o ponto mais elevado da compreensão musical: tais efeitos fazem o ouvinte descer quase ao mesmo nível da besta ${ }^{9}$. Outro defeito da música grega reside em sua união com as outras artes e disciplinas que lhe são exteriores: a dança, a poesia, o mimo, a filosofia, a educação. Isso prova que ela é uma arte subordinada à expressão de conteúdos estrangeiros e, portanto, muito distante do ideal de música absoluta defendido por Hanslick ${ }^{10}$.

A doutrina do ethos "modal" constitui mais um elemento que atesta sua imperfeição: os gregos associam esse ou aquele "modo" a uma função (expressar a tristeza, acompanhar os banquetes, inflamar a coragem) que provocaria assim efeitos "patológicos" espetaculares que a tradição literária relatou até o século XIX. Mas, segundo Hanslick, não se deve deplorar o desaparecimento de tal código $^{11}$. Assim, a música grega é condenada em nome do progresso da arte: a arte musical não se submeteu a um processo de degeneração que a teria feito perder sua perfeição natural original.

9 HANSLICK, E. Du Beau musical. Trad. Alexandre Lissner, Paris: Hermann, 2012, p. 169-170.

10 Ibid. p, 171.

11 Ibid. p, 172-173.

68 I Cad. Nietzsche, São Paulo, n. 34 - vol. I, p. 61-98, 2014. 
Na verdade, a música é uma arte artificial que conheceu numerosos aperfeiçoamentos ao longo de sua história: nem a melodia nem a harmonia são dados naturais, pois elas são construções humanas, melhoradas no curso dos séculos até atingir o ponto da constituição do sistema harmônico da Europa moderna. Ora, pela razão de terem ignorado a harmonia tonal ao passo que davam prioridade ao "recitativo", a música "elementar" dos gregos deve ser ultrapassada pela música moderna ${ }^{12}$ :

Tudo o que nós conhecemos [da] música [dos gregos] conduz com muita probabilidade a concluir que a música agia de maneira puramente sensível, o que não exclui um certo refinamento. A música como arte, no sentido moderno, não existia na antiguidade clássica; ela teria desempenhado um papel tão importante para os desenvolvimentos posteriores quanto a poesia, a escultura e a arquitetura. $\mathrm{O}$ gosto dos gregos pelo estudo sistemático das relações tonais mais sutis é puramente científico e não tem nenhuma relação com nosso propósito. [...] A música moderna se isenta de um refinamento melódico que empregava até o quarto do tom e o gênero enarmônico; e também dispensa a aptidão particular de cada modo a casar a língua falada ou cantada ${ }^{13}$.

Hanslick evoca aqui de maneira breve a teoria dos intervalos estabelecidos a partir de cálculos pitagóricos: os intervalos "consoantes" (symphoniai) são a quarta, a quinta e a oitava; os intervalos de terça e de sexta, de segunda e de sétima são classificados como intervalos "dissonantes" (diaphoniai). Além disso, no interior do intervalo de quarta (tetracorde formando a base do sistema musical grego), dois sons móveis estão inseridos, mas suas posições variam de acordo com os três gêneros (diatônico, cromático, enarmônico); num caso, do gênero enarmônico, os dois sons móveis

12 Ibid. p, 172.

13 Ibid. p, 171. 
estão separados por um quarto de tom. As divisões do tom, atestadas desde os pitagóricos, tinham sido criticadas por Platão: Sócrates, no livro VII da Republica, zomba dos harmonistas "triturando" as cordas para calcular microintervalos que escapam da audição, enquanto que Aristóxeno de Tarento critica os cálculos pitagóricos em Elementos harmônicos ${ }^{14}$.

Ora, como sublinha Hanslick, tais cálculos não apenas testemunham uma abordagem "científica" da música que diz respeito à especulação metafísica ou a uma análise matemática dos sons, mas esses microintervalos desapareceram completamente da música erudita do Ocidente ${ }^{15}$. Portanto, os gregos se assemelham aos povos orientais, entre os quais predomina a música vocal, inferior à música instrumental:

Os gregos não conheciam a harmonia, mas cantavam em oitava ou em uníssono como fazem ainda hoje essas tribos asiáticas nas quais a cultura musical é sobretudo vocal. [...] 0 povo mais artista da Antiguidade, bem como os músicos mais instruídos do início da Idade Média não podiam sequer fazer como nossas pastoras dos Alpes: cantar em terças ${ }^{16}$.

Em Vom Musikalisch-Schönen ${ }^{17}$, a música grega antiga, é, portanto, privada de sua condição de modelo: os gregos são relegados

14 PLATON. République, VII, 531a. Sobre os cálculos dos harmonistas e as críticas de Aristóxenes de Tarento contra eles, C.f. BÉLIS, A. Aristoxène de Tarente et Aristote: le Traité d'Harmonique. Paris: Klincksieck, 1986, p. 88-115.

15 HANSLICK, E. Du Beau musical, op. cit. p, 172.

16 Ibid.p. 183.

17 Obra de estética pura em que a História é deliberadamente deixada de lado. Hanslick critica claramente a estética de Hegel e distingue categoricamente a história da arte (história social, história biográfica) e estética pura (Ibid. p, 129-131). 
às "primeiras etapas da civilização" pois a música deles, "sensível e simbólica"18, não era "uma arte no sentido em que nós a compreendemos"19.

Desde 1869-1870, Nietzsche reagiu a esse assalto sistemático liderado pela nêmeses de Wagner: o aluno de Ritschl, apoiando-se sobre seu profundo conhecimento de teoria e história da música grega, inverte as teses de Hanslick opondo a elas argumentos filológicos destinados também a justificar o drama de Wagner cuja sombra paira sobre toda a conferência e que, na última frase, é evocado. A avaliação do teatro musical helênico proposta por Nietzsche é, portanto, radicalmente oposta àquela de Hanslick. Em primeiro lugar, o autor de uma tragédia era comparado a um atleta de pentatlo que reunia as diferentes disciplinas artísticas em apenas uma obra de arte (GMD/DM, KSA 1.529). Por outro lado, a música, na Grécia, era essencialmente vocal, enquanto que a música instrumental era apenas uma arte de „virtuose“ de origem ,asiática“20; a música "absoluta” não existia porque os gregos fruiam do texto e da música ao mesmo tempo, ao contrário dos modernos que se tornaram incapazes de realizar esse tipo de fruição ${ }^{21}$. No drama, a música era um "meio" e não um "fim”, pois ela deveria despertar a piedade na alma do espectador-auditor de modo mais eficaz que a palavra, já que ela "toca imediatamente o coração" e "é a verdadeira língua universal, compreendida em todos os lugares" 22 .

O efeito das representações dramáticas sobre o público grego se explicava por três fatores. Pela grandiosidade do objeto representado que unia plástica e música; pela origem da tragédia a qual estava primitivamente ligada aos rituais de fecundidade em

18 Ibid., p. 171

19 Ibid., p. 170.

20 Ibid.

21 Ibid.

22 Ibid, p, 528. 
homenagem a Dioniso e Demeter que colocavam seus adeptos em transe coletivo; e, por fim, pela presença do coro, matriz da tragédia, no seio do qual se fundem o público e os coreutas numa comunicação íntima com o herói sofredor. Enfim, se a música era muito pobre do ponto de vista harmônico e melódico, essa "pobreza" era compensada por uma grande riqueza rítmica ${ }^{23}$. A resposta de Nietzsche a Hanslick no que concerne a esse último ponto é muito clara: para o filólogo, a harmonia, ainda que ela fosse pobre, já estava presente na música grega:

É verdade que, ainda hoje, é bastante disseminada a opinião que defendia que a música grega não era de maneira nenhuma uma língua universalmente inteligível. A música seria um mundo sonoro inventado pela ciência, deduzido de uma teoria acústica e completamente estrangeiro para nós. Difunde-se também, por exemplo, a falsa ideia que a terça maior teria sido sentida na música grega como uma dissonância. Deve-se livrar-se de tais ideias e ter em mente que a música dos gregos é mais próxima de nosso gosto do que a música da Idade Média ${ }^{24}$.

Reconhece-se Hanslick por detrás do sujeito indefinido, pois identificamos facilmente sua crítica contra a música grega: contra Hanslick, Nietzsche afirma que a musica grega é uma música exemplar e perfeita por sua universalidade. Universalidade que o filólogo-filósofo tenta demonstrar através do conhecimento parcial dos princípios de harmonia. Ao passo que Hanslick colocava a arte musical grega no mesmo nível do descanto medieval (pela razão de ter ignorado a terça), Nietzsche separa os gregos dos homens da idade média e assimila o gosto deles àquele dos modernos. Isso de fato é realizar uma reviravolta notável em relação aos trabalhos dos historiadores da música que haviam claramente colocado em

23 Ibid. p, 530.

$24 \quad$ Ibid. p, 529.

72 I Cad. Nietzsche, São Paulo, n. 34 - vol. I, p. 61-98, 2014. 
evidência a evolução da música no Ocidente mostrando que a polifonia harmônica se desenvolveu na segunda metade do período medieval. Contudo para Nietzsche, uma tal oposição é a partir de agora caduca já que está provado que os gregos já tinham percebido a terça maior como um intervalo não "dissonante".

Por que realçar este intervalo? Porque a terça maior tem uma função essencial na tonalidade harmônica tal como ela aparece no final da Idade média ${ }^{25}$. O nó do problema reside na apreciação desse intervalo: os pitagóricos, por meio de seus cálculos, haviam determinado um intervalo de dois tons equivalendo a uma terça, mas essa terça era falsa em relação ao intervalo puro; a soma de dois tons ou "dítono", fornecida pela aritmética pitagórica "científica", não concorda com a terça natural fornecida pela ressonância. Entretanto, para Nietzsche, é preciso distinguir os cálculos pitagóricos da percepção auditiva dos "gregos": eles deviam ouvir "desafinação" do dítono em relação a terça maior natural. Compreende-se assim o argumento esboçado por Nietzsche: se os gregos foram sensíveis à terça ao ponto de não "senti-la" (empfinden) como sendo uma "dissonância", então eles perceberam a importância desse intervalo fundamental na constituição da polifonia tonal a partir do século XVI. Sem levar em conta o período medieval, ao longo do qual a terça não estava em uso na polifonia coral, haveria, portanto, uma forma de continuidade entre a música antiga e a música moderna.

$\mathrm{O}$ alcance desse argumento só pode ser compreendido no contexto do pensamento que admite como norma universal o regime harmônico moderno: nesse domínio, Nietzsche aborda a música grega com os mesmos pressupostos de Hanslick ${ }^{26}$. Pode-se é claro

25 Cf. CHAILLEY, J. Traité historique d'analyse harmonique. Paris: Leduc, 1977, p. 34-37.

26 Ao contrário de Rousseau que, um século antes, havia indicado a incompatibilidade fundamental da música monódica grega com o sistema harmônico moderno no capítulo XIX de Essai sur l'origine des langues. Segundo Rousseau, a terça, que não figurava entre as consonâncias para os gregos, fornece a prova de que a melodia grega era essencialmente diferente da harmonia "gótica" (cf. ROSSEAU, J-J. EEuvres complètes. V, Paris: La Pléiade, 1995, p. 423-424). 
falar de "projeção" pessoal de um estado da música ocidental sobre uma música antiga monódica e "modal" essencialmente diferente, mas Nietzsche não é o único a propor essa tese, que ele evoca de uma maneira muito alusiva em Drama musical grego. Para contestar Hanslick, ele pode se apoiar em obras científicas recentes. Por exemplo, em Lehre von den Tonempfindungen als physiologische Grundlage für die Theorie der Musik (1863), que Nietzsche lê em $1870^{27}$, Hermann von Helmholtz assimila os graus do octacorde aos graus harmônicos de uma escala moderna: a mese, nota mediana do sistema, corresponderia à tônica, enquanto que a hypate seria a dominante ${ }^{28}$. Em razão dessa identidade de funções, todas submetidas ao "princípio da tonalidade", Helmholtz pode supor que "os gregos, que fizeram nascer nossa gama diatônica, não estavam de maneira nenhuma desprovidos do sentimento de tonalidade do ponto de vista estético; apenas esse sentimento não era ainda tão claramente destacado quanto na música moderna e, sobretudo, ao que parece, ele não possuía nenhum papel bem caracterizado nas regras técnicas da construção melódica"29.

Tal assimilação da música grega pela música moderna é igualmente realizada por Rudolf Westphal, um dos historiadores que Nietzsche, em 1872, utiliza para se contrapor a Wilamowitz ${ }^{30}$ : em a Metrik der Griechen, Westphal sustenta que os gregos empregaram todos os intervalos diatônicos no seio de um sistema polifônico análogo àquele dos modernos:

Sobre a polifonia da instrumentação dentro da música antiga - utilizávamos a polifônica em todos os lugares apenas em oposição ao

27 Cf. GÜNTHER, F. F. Rhythmus beim frühen Nietzsche, op. cit. p, 29 e 75-77.

28 HELMHOLTZ, H. Théorie physiologique de la musique. Trad. G. Guéroult. Paris: Victor Masson, 1868. p, 314-316.

29 Ibid. p, 316. Sobre a assimilação da tonalidade e da música grega no fim do século XIX, Cf. CHAILLEY, J. Traité historique d'analyse harmonique, op. cit. p, 80-81.

30 Carta de Friedrich Nietzsche a Erwin Rohde, 16 de Julho de 1872, Correspondance Avril 1869 - Décembre 1874. Paris: Gallimard, 1986, p, 313-314.

74 I Cad. Nietzsche, São Paulo, n. 34 - vol. I, p. 61-98, 2014. 
uníssono - as ideias compreensivo-imaginativas permaneceram muito incertas. Nós vamos fornecer a prova incontestável, de que apenas o canto era em uníssono, contrastando com este os instrumentos de acompanhamento, que se comportavam polifônicamente, de modo que, aquilo que chamamos de harmonia, no entanto, estava presente e, que de modo algum as vozes que acompanham estavam limitadas às quintas, quartas e oitavas, mas também que a terceira a sexta, a sétima e a segunda também tinham seu lugar na música antiga ${ }^{31}$.

Desde o início do século XIX, a existência de uma heterofonia, a „parafonia“ foi estabelecida com o lançamento dos estudos de Böckh (que considerava, inclusive, que traços de polifonia harmônica haviam aparecido na Grécia antiga) ${ }^{32}$ : trata-se do acréscimo intermitente, sob a linha vocal, de notas pertencentes aos intervalos consonantes (oitava, quinta, quarta). Westphal afirma, por seu turno, que a krousis fazia ouvir um acompanhamento instrumental "sob o canto" e revelava a existência de uma polifonia instrumental: Em Die Geschichte der griechischen und mittelalterlichen Musik (1865), ele explica que os gregos praticavam a harmonização do canto desde a época arcaica:

Temos agora de salientar aqui, que a opinião vulgar, na qual a música antiga era em uníssono, fundamenta-se em um uso deficiente das fontes. No entanto, o canto era em uníssono, a polifonia era produzida por acompanhamento instrumental, que era chamado de hypo tèn krousin $[\ldots]^{33}$.

31 ROSSBACH, A.; WESTPHAL, R. Metrik der Griechen im Vereine mit dem übrigen musischen Künsten. Leipzig: Teubner, 1867, p. 260.

32 BÖKH, A. De Metris Pindari. In: Pindari Opera quae supersunt, I, Leipzig: Weigel, p. 253-257.

33 WESTPHAL, R. Geschichte der alten und mittelalterlichen Musik. Breslau: Leuckart, 1865, p. 24. 
Compreende-se por consequência porque Nietzsche pode declarar em Drama musical grego: "Eu já indiquei que o canto coral se distingue do solo apenas pelo número de participantes e que somente os instrumentos de acompanhamento tem o direito a uma multiplicidade de voz, inclusive muito reduzido, ou seja, a uma harmonia no sentido atribuído a esse termo" (GDM/DM, KSA 1.530). Consequentemente é falso pretender, como fez Hanslick, que os gregos tenham ignorado a harmonia: eles tiveram a intuição da harmonia moderna de tal modo que o desenvolvimento da música europeia está enraizado no drama musical grego.

Num primeiro momento, este é o embasamento histórico e filológico no qual Nietzsche se apoia para contestar Hanslick. Contudo, enquanto que o Drama musical grego é um texto predominantemente filológico, ao longo do ano de 1870 a questão da harmonia toma pouco a pouco uma dimensão metafísica na reflexão de Nietzsche, notadamente a partir do momento em que ele descobre o Beethoven de Wagner.

Harmonia, ritmo, dinâmica: metafísica e música grega

A teoria da harmonia preocupou longamente Nietzsche durante a elaboração de $O$ nascimento da tragédia, a esse respeito testemunham não só a Visão dionisíaca de mundo, mas também diversos cadernos em que a pesquisa sobre essa questão pode ser verificada. Nesses textos (P I 15 datando do inverno de 1869 e da primavera de 1870, U I 2 datando do fim de 1870 e do início do ano 1871 e U I 4 datando do ano 1871), dos quais o filósofo não utilizará todos elementos em suas obras publicadas, a reflexão dos filólogo se volta notadamente sobre a definição da essência da música a partir de três elementos essenciais (harmonia, ritmo, dinâmica) e a relação destes como a Vontade.

Sabe-se que um dos livros mais importantes para a elaboração de $O$ nascimento da tragédia foi o Beethoven concebido por Wagner 
em 1870 por ocasião do centenário do compositor. Nas considerações estéticas que integram a primeira parte do opúsculo, Wagner faz uso de Schopenhauer e considera a música uma língua universal atribuindo-lhe a faculdade de exprimir as paixões, faculdade proveniente da própria origem da música. Distinguindo a vista e o ouvido, Wagner expõe o processo por meio do qual o som é engendrado: o artista, submetido a uma visão de sonho, extrai-se brutalmente dessa contemplação muda e interior por um grito manifestando sua emoção e revelando-a ao mundo exterior. Esse grito, expressão imediata da Vontade, é natural e universalmente compreensível sem conceito. A tarefa do musicista é transformar esse grito primitivo em som musical e exprimir assim todas as nuances da Vontade; para isso, ele emprega uma paleta sonora que se estende "do grito de horror até os jogos consoladores das harmonias felizes" $"$.

Mas se Wagner descobre a origem antropológica da música na emoção e no grito, a música é por essência harmonia. Conservando a distinção romântica entre plástica e música, Wagner opõe a harmonia que, fora do espaço e do tempo, é matéria sonora, e a força "plástica" do ritmo, através da qual a harmonia adquire forma e determinação. Enquanto em Ópera e Drama (I, 7), a essência da música era melódica (harmonia e ritmo eram apenas a infraestrutura), a melodia, em Beethoven, passa ao segundo plano na história da música: é nos gregos que ela foi cultivada à perfeição, numa civilização em que o espírito da música estava presente em toda parte; mas "o Paraiso" foi perdido e "o mundo vive a estancar a fonte de seu movimento"35. Aos olhos de Wagner, na época moderna a melodia está associada a gêneros caducos e a musicistas secundários, nos quais o ritmo periódico e regular é predominante (Haydn, os compositores da grande ópera romântica). É apenas com Beethoven que ela é regenerada, como Wagner já havia declarado em Oper und

34 WAGNER, R. Beethoven. Trad. Jean-Louis Crémieux-Brilhac. Paris: Gallimard, 1970, p. 97. 35 Ibid. p, 165. 
Drama (Ópera e Drama); o drama lírico, fundado sobre o princípio da "melodia infinita", marca o remate dessa regeneração, a melodia estando doravante reconciliada com a harmonia.

O lugar preeminente da harmonia em Wagner durante os anos 1860 é atestado por sua prática de compositor em Tristão e Isolda, cujos contornos melódicos definidos segundo as normas clássicas (cadencias perfeitas, regularidade métrica) estão apagados, o que mergulha o ouvinte num "mar schopenhaueriano de sons"36. Vontade e harmonia tornam-se indissociáveis: os afetos dos personagens, em particular de Tristão, são exprimidos pelas modulações constantes, as suspensões, appoggiaturas, os acordes de sétima e de nona, a instabilidade tonal onde as cadências são evitadas e o som "afogado"37. É a harmonia, associada a uma dinâmica contrastante e a uma rítmica liberada do esqueleto de compassos, e fundada sobre uma agógica de uma extrema mobilidade (conforme os princípios expostos por Wagner no seu ensaio Über das Dirigiren de 1869), que deve traduzir a Vontade bem melhor que a solitária melodia planando sobre um acompanhamento harmônico limitado.

É a partir do verão de 1870 que Nietzsche começa a adaptar a teoria estética do Beethoven e a metafísica histórica de Schopenhauer a seu próprio projeto histórico-filosófico ${ }^{38}$ : ele interpreta a poesia lírica grega como um processo estético "eterno", transhistórico, que consiste na união de duas "pulsões" naturais, a pulsão apolínea (plástica e visual) e a pulsão dionisíaca (musical e auditiva). Desde o verão de 1870, A visão dionisíaca de mundo e os fragmentos póstumos contemporâneos revelam os grandes traços

36 Carta de Friedrich Nietzsche a Erwin Rohde, s/d. [fim novembro-inpicio de dezembro de 1868], Correspondance, I, Juin 1850 - Avril 1869, Paris, Gallimard, 1986, p. 632.

37 Cf. DUFOUR, E. L'esthétique musicale de Nietzsche, op. cit., p. 91-93.

38 GT/NT 16, KSA 1.104. Cf. BRUSE, Klaus-Detlef. "Die griechische Tragödie als 'Gesamtkunstwerk' - Anmerkungen zu den musikästhetischen Reflexionen des frühen Nietzsche”. In: Nietzsche Studien, 13, 1984, p. 165-176. 
dessa interpretação, a qual repousa sobre um pressuposto que já estava presente em Drama musical grego: a universalidade da música grega na sua dupla dimensão rítmica e harmônica.

No que concerne ao desenvolvimento histórico da harmonia, a Visão dionisíaca de mundo expõe uma tese que adianta o fim do capítulo 2 de $O$ nascimento da tragédia. Na segunda seção, um breve relato narra o nascimento da harmonia na Grécia: do Drama musical grego, Nietzsche conserva implicitamente a tese de uma heterofonia ligada ao coro ao emprego de um acompanhamento de instrumentos de sopro. A música arcaica, que introduziu na Grécia a embriaguez e o êxtase face ao mundo apolíneo da bela aparência, se caracteriza então pela irrupção da harmonia e por uma rítmica nova que Nietzsche explora nos seus cursos do semestre de inverno de 1870-1871 e nos Rhythmische Untersuchungen. Essa rítmica desbridada corresponde historicamente à eclosão da poesia lírica na Grécia, em que os versos bastante variados, associados ao aulo, rompem a monotonia do hexâmetro datílico da epopeia apolínea:

[...] a rítmica, que se movia até então em um ziguezague dos mais simples, desata seus membros na dança das bacantes; o som se fez ouvir, não mais como numa extenuação fantasmática de outrora, mas multiplicado por uma massa de milhares de homens e acompanhado por instrumentos de sopro de ressonância profunda (tieftönender Blasintrumente). E o acontecimento mais misterioso se produziu: a harmonia veio ao mundo, cujo movimento leva a vontade da natureza a uma intelecção imediata (DW/VD 2, KSA 1.565) ${ }^{39}$.

Nietzsche menciona aqui as duas partes essenciais da música, rítmica e harmonia ("rítmica e harmonia são as partes principais, a melodia é apenas uma abreviação da harmonia", escreve o autor

39 Tradução de Jean-Louis Backès.

Cad. Nietzsche, São Paulo, n. 34 - vol. I, p. 61-98, 2014. 
durante o inverno de 1869-1870) ${ }^{40}$. Essa posição subalterna da melodia é semelhante àquela que ela ocupa na música de Wagner: a melodia, ligada ao mundo artificial da música apolínea, é secundária em relação à harmonia, essência da música cuja origem é natural.

Essa não é a única relação com Beethoven: da mesma forma que Wagner, Nietzsche considera que a música tem sua origem no grito enquanto exteriorização da Vontade. De fato, o gesto e o som constituem os meios universais pelos quais a Vontade se manifesta. Todavia, ao passo que o gesto pertence ainda à representação (Vorstellung), o som se faz presente por meio de uma simbologia não conceitual. Ou seja, sob essas três dimensões (rítmica, dinâmica e harmônica), o som é o símbolo da Vontade. No grito, fenômeno antropológico universal, "a essência da coisa se encontra expressa pela entonação, altura, ritmo" (Nachlass/FP 1869-1870, 3 [15], KSA 7.63): o grito contém, portanto, em termos musicais, a dinâmica, a harmonia e a rítmica. Nota-se, além disso, uma gradação da rítmica em direção da dinâmica e harmonia: a rítmica manifesta a Vontade por meio de „formas intermitentes“(Intermittenzformen); a dinâmica indica as variações no grau de prazer e de desprazer; a harmonia é o "símbolo da essência da Vontade" (Symbol der reinen Essenz des Willens) e, por essa razão, ela escapa totalmente do conceito. Nesse sentido, ela está intimamente associada a Dioniso, cujo culto tem suas raízes cravadas na Natureza ${ }^{41}$. Além disso, de acordo com um fragmento filosófico do início do ano de 1870, parece que a origem da harmonia foi concebida por Nietzsche como um fenômeno de resposta: "grito e contra grito: a força da harmonia" (Nachlass/FP 1869-1870, 3 [16], KSA 7.64). Essa anotação deixaria entrever a origem da harmonia no fenômeno espontâneo da resposta, que Wagner havia evocado a respeito dos cânticos populares montanheses e venezianos ${ }^{42}$.

$40 \quad$ Nachlass/FP 1869-1870, 3 [54], KSA 7.75.

41 DW/VD 4, KSA 1.574. Cf. Nachlass/FP 1869-1870, 3 [19], KSA 7.65.

42 WAGNER, R. Beethoven, op. cit., p, 95-96.

80 I Cad. Nietzsche, São Paulo, n. 34 - vol. I, p. 61-98, 2014. 
A essa origem antropológica soma-se uma dimensão teórica e metafísica acerca da qual Nietzsche reflete durante o período de elaboração de $O$ nascimento da tragédia. De fato, em vários fragmentos de 1870 e 1871, o filólogo medita sobre a possibilidade de uma concepção filosófica de harmonia tonal. Nesses textos, ele toma como referência o modelo Schopenhauer que, no parágrafo 52 de Mundo como Vontade e representação, havia definido a música como a arte metafísica por excelência, estabelecendo uma analogia entre a hierarquia da natureza e a hierarquia das vozes musicais. Assim, desenvolvendo o conceito schopenhaueriano de negação do sofrimento, que estaria presente na música, Nietzsche considera que a harmonia é essencialmente negativa: "A harmonia prova até que ponto é válido o princípio da negatividade" (Nachlass/FP 1870-1871, 7 [28], KSA 7.145). O sistema harmônico moderno, que é uma cópia imediata da Vontade enquanto ela unifica a multiplicidade (Nachlass/FP 1869-1870, 3 [14], KSA 7.63) ${ }^{43}$, consiste em excluir os harmônicos superiores introduzindo intervalos irracionais em relação ao som fundamental que os gera. É sob essa condição que pode nascer o "sentimento de harmonia": "O que é a sensibilidade para a harmonia? Por um lado, unicamente a subtração dos tons consoantes superiores, por outro, a não-audição individual dos mesmos" (Nachlass/ FP 1870-1871, 7 [118], KSA 7.166). Graças a essa subtração dos harmônicos superiores, o „sentimento de harmonia“ repousa sobre o prazer propiciado pelo acorde perfeito maior cujos intervalos são fornecidos pelos cinco primeiros harmônicos. A dissonância surge com a sétima harmônica: essa harmônica (que em sua forma pura não pode integrar o temperamento igual) permite introduzir a partir do século XVII

43 Cf. DUFOUR, E. L'esthétique musicale de Nietzsche. op. cit. p, 93-94. 
o acorde de sétima, isto é, um acordo de quatro sons dissonantes que devem estar resolvidos por um acorde perfeito sobre a tônica; segundo o solfejo clássico, a sétima é uma dissonância ${ }^{44}$.

É assim que, no campo da estética, o acordo de três sons, fundamento da harmonia tonal, se confunde com a beleza: harmonia e beleza são aparências que violam a realidade da natureza, caótica e desarmônica (cf. Nachlass/FP 1870-1871, 7 [27], 7 [116], 7 [117], KSA 7.143, 164, 165). A negação das harmonias superiores é a condição para criar uma arte musical harmoniosa, consonante e consolador: a representação atenua o efeito perturbador das dissonâncias contidas no próprio som. Essa união da consonância e da dissonância, da harmonia e do desarmônico numa representação que protege o ouvinte do perigo da música será retomado no capítulo 24 de $O$ Nascimento da tragédia, onde a beleza harmoniosa e o mito trágico lançam um véu de beleza sobre a fealdade e a desarmonia dionisíaca. É sobre esse fundo musical dissonante que se edifica a beleza eurrítmica e harmônica, plástica e apolínea, que Nietzsche evoca no último capítulo de $O$ Nascimento da tragédia.

A principal dificuldade reside na passagem dessa estética musical de inspiração schopenhaueriana à história da música grega arcaica. Aqui, Nietzsche é confrontado com um problema central: o valor exemplar da música grega ${ }^{45}$. Pode-se convocar essa arte para ilustrar o nascimento da música nos primórdios da humanidade? Nietzsche começa por contestar uma tese estética que desde o ensaio de Schiller Sobre a poesia ingénua e sentimental (1795) gozava de uma hegemonia: a oposição entre a "música" e "plástica", a primeira sendo apanágio dos Modernos, a segunda dos Antigos. Contra essa distinção entre uma arte grega plástica "objetiva" e uma arte moderna musical "subjetiva", Nietzsche sustenta que a unidade entre plástica e música já existia na Grécia antiga:

44 Cf. CHAILLEY, J. Traité historique d'analyse harmonique. op. cit. p, 43-47.

45 Sobre o valor do exemplo histórico e sua subordinação à filosofia, verificar sobretudo: Nachlass/FP 1871, 9 [42], KSA 7.228. 
“A ideia de que o mundo grego seja caracterizado pela plástica e o mundo moderno pela música é totalmente falsa. $\mathrm{O}$ mundo grego possui, ao contrário, a união perfeita entre o apolíneo e o dionisíaco" (Nachlass/FP 1871, 9 [120], KSA 7.318).

Esse é o próprio fundamento da tese de $O$ Nascimento da tragédia: música dionisíaca e plástica apolínea já estavam reunidas na poesia lírica e na tragédia. Desde 1869, no fragmento 1 [54], Nietzsche já mencionava a união estreita de todas as artes gregas no teatro e nos templos (poesia, música, dança, arquitetura, escultura), antes de inverter de forma espetacular o caráter alocado à música moderna e à grega: "imperfeição moderna em virtude da qual a teoria determina que se deva fruir das artes isoladamente: o que coincide com o desenvolvimento da capacidade particular. A harmonia é característica do helênico, a melodia dos modernos (enquanto característica absoluta)" (Nachlass/FP 1869, 1 [54], KSA 7.27).

Tal reviravolta é notável: a simplicidade da "linha" monódica antiga era enriquecida pelas diversas "cores" de um acompanhamento harmônico? Retomando uma comparação tradicional já utilizada por Rousseau no Ensaio sobre a origem das línguas (XIII-XIV) e por Gluck no prefácio de Alceste parisiense (mencionada em Drama musical grego), Nietzsche propõe uma equivalência entre melodia vocal (a poesia) e o desenho de um lado, e o acompanhamento harmônico instrumental e a cor de outro. A descoberta da policromia nas artes plásticas gregas - até o início do século XIX, a policromia era considerada uma prática oriental e a brancura era entendida como um atributo da arte grega. Esta tese é colocada em evidência, sobretudo, por Winckelmann - é, aliás, um fato importante que constitui um precedente (GDM/DM, KSA 1.518). Nietzsche faz alusão ao debate sobre a policromia nas artes plásticas que suscitou reações apaixonadas no período de 1830-1860 entre os historiadores europeus de arte. Alguns, como Raoul-Rochette, continuarão partidários da brancura uniforme dos monumentos gregos, 
outros, como Hittorff, Gottfried Semper e Quatremère de Quincy, se apoiam nos dados arqueológicos que revelam o uso da pintura policrômica sobre os templos e estátuas ${ }^{46}$.

Para exaltar a policromia, a noção de harmonia foi exposta por Semper e por Hittorff: harmonia externa com a paisagem mediterrânea, harmonia interna com o edifício ${ }^{47}$. Da mesma forma, segundo Nietzsche, essa policromia provocava um efeito de ordem "harmônica": "Nenhum sombreamento das cores. Significado. Detalhes são assim destacados. Efeito harmonioso do todo através da simetria de cores"48. No domínio musical, a policromia poderia encontrar um equivalente na polimodalidade, isto é, a diversidade de modos corresponderia à diversidade de cores. Parece que Nietzsche vislumbrou a possibilidade de interpretar o sistema das harmoniai gregas nesse sentido. Ele teria percebido aí um esboço de harmonia tonal. É o que parece indicar o fragmento 3 [40] do inverno de 1869-1870:

A música apolínea - aparentada às artes plásticas quanto a sua significação rítmica.

Embriagar o coração nunca foi a finalidade da música apolínea, antes ela possuía uma ação pedagógica.

Em oposição, o efeito orgiástico da música.

No caráter [Charakter] das diferentes escalas [Tonleitern], instintivamente revela-se a HARMONIA (Nachlass/FP 1869-1870, 3 [40], KSA 7.72).

Reconhece-se aqui o princípio apolíneo "plástico” e o princípio dionisíaco "orgiástico" associados aos dois elementos essenciais da música, ritmo e harmonia. A particularidade dessa reflexão

46 Cf. GRAND-CLÉMENT, A. "Couleur et esthétique classique au XIX ${ }^{\mathrm{e}}$ siècle : l'art grec antique pouvait-il être polychrome ?» In Ithaca. Quaderns Catalans de Cultura Clàssica, 21, 2005. p, 139-160 ; JOCKEY, Philippe. Le mythe de la Grèce blanche. Paris: Belin, 2012. 47 GRAND-CLÉMENT, A. "Couleur et esthétique classique au XIX" siècle : l'art grec antique pouvait-il être polychrome?», op.cit. p, 148-152.

48 Encyclopädie der klassischen Philologie, KGW, II 3, p, 386.

84 I Cad. Nietzsche, São Paulo, n. 34 - vol. I, p. 61-98, 2014. 
reside antes na menção de "escalas" e de seu caráter, que é colocado em relação com o efeito orgiástico da música. Nietzsche faz primeiramente alusão ao "caráter" das harmoniai: trata-se do caráter ético ou de sua própria constituição? No primeiro caso, Nietzsche se referiria então à teoria do éthos de "modos", atestada por numerosos textos e cujo filólogo aparentemente se recorda em a Visão dionisíaca de mundo quando ele evoca a irrupção do dionisismo no seio do mundo homérico: "Na embriaguez dionisíaca, no cortejo louco, delirante, através de todas as escalas da alma (Seele-Tonleitern), provocadas pelas excitações narcóticas e o arrebatamento dos instintos primaveris, tal como a natureza se exprime em sua força mais alta; ela reúne novamente os seres isolados e se faz experimentar como unidade [...]" (DW/VD 2, KSA 1.557).

Sem dúvida alguma, esses Seele-Tonleitern não constituem uma simples metáfora: poderia se tratar das harmoniai, que possuíam cada uma um éthos particular e cujo caráter havia sido avaliado por Platão e Aristóteles segundo sua utilidade para a educação do cidadão. No livro III da República (398d-399c), Platão, inimigo da poikilia e do orgiástico, almeja suscitar a temperança e a coragem na alma do ouvinte. Ele distingue as harmoniai lícitas das harmoniai ilícitas: as primeiras, dóricas e frígias, suscitam o ardor guerreiro e a tranquilidade pacífica; as outras (lídias, jônicas) desregram a alma, em particular quando são executadas por meio de aulos e instrumentos com muitas cordas. Aristóteles não se distancia muito de Platão no livro VII da Política concordando como a primazia da harmonia dórica e acrescentando as harmoniai lídia e frígia $^{49}$ : em Aristóteles, como também em Platão, é a temperança e o domínio de si que são privilegiados na música.

Contra esse uso político e pedagógico da música, que se caracteriza por conjurar os efeitos potencialmente deletérios, Nietzsche

49 ARISTOTE. Politique, VIII, 7, 1342 a-b. Cf. BÉLIS, Annie Aristoxène de Tarente et Aristote, op. cit., p, 57-59. 
valoriza a aulética e a multiplicidade de ethè provocada pelo conjunto das harmoniai. De fato, antes de Platão e Aristóteles, que desvalorizaram a música em benefício da palavra e da racionalidade, a arte poético-musical arcaica tinha adquirido uma grande expressividade que a tragédia original explorou em seguida: "Influência da música antiga extraordinariamente marcada sobre os afetos. A música antiga é concebida como linguagem da vontade, de onde se explica seu laço indissolúvel com a poesia lírica" (Nachlass/ FP 1871, 9 [119], KSA 7.318). Tal influência sobre os afetos pode se explicar pelo éthos das harmoniai (júbilo, tranquilidade, ardor guerreiro, amolecimento), que são maneiras de exprimir a Vontade. Enquanto Platão reduziu essa pluralidade apenas às harmoniai dórica e frígia, os gregos da época arcaica e pré-clássica possuíam pelo menos seis (cujo traço encontramos notadamente na lista de Aristides Quintiliano concernindo as harmoniai platônicas muito antigas) $)^{50}$, o que aumentava o efeito musical de suas composições: assim, o nómos aulético compreendia cinco partes compostas nos cinco modos diferentes, como nota Nietzsche em seu curso sobre os poetas líricos gregos ${ }^{51}$. Do ponto de vista da teoria musical, essas "escalas" revelam então a presença latente da harmonia tonal como mostra o fragmento 3 [40]: da mesma forma que o indivíduo é instintivamente poeta-músico-coreógrafo (DW/VD 3, KSA 1.567), a harmonia aparece espontaneamente na prática musical antes de ser determinada pela doutrina dos Números de Pitágoras, filosofia apolínea por excelência (cf. Nachlass/FP 1870-1871, 7 [62], KSA 7.152). Nietzsche retoma essa ideia em Visão dionisíaca de mundo:

A música de Apolo era uma arquitetura dórica de sons, mas de sons apenas indicados, como sons próprios da cítara. Toma-se cuidado de afastar precisamente o elemento característico da música dionisíaca e mesmo da

50 Aristide Quintilien, De Musica, I, 9 (Meibom 22 = BARKER, Andrew. Greek Musical Writings, II, Cambridge, Cambridge University Press, 1989, p, 440).

51 Die griechischen Lyriker, KGW, II 2, p, 111.

86 I Cad. Nietzsche, São Paulo, n. 34 - vol. I, p. 61-98, 2014. 
música em geral, a potência de abalo do som e o mundo absolutamente incomparável da harmonia. $\mathrm{O}$ grego tinha para com ela o sentimento mais delicado, como nós devemos deduzi-lo da característica estrita dos modos (Tonarten), ainda que a necessidade de uma harmonia realizada, efetivamente escutada, seja para ele de importância bem inferior que para o mundo moderno. Na sequência das harmonias (Harmonienfolge), e já em sua compilação, no que chamamos de melodia, a "vontade" se revela imediatamente, sem ser antes integrada a um fenômeno (DW/VD 2, KSA 1.557).

Um deslizamento decisivo se produz aqui em relação ao fragmento 3 [54]: a melodia é a compilação das "harmonias" e não mais da harmonia. Visto que os dois termos se sobrepõem, a diferença entre a música moderna e a música grega depende da sensibilidade dos povos em relação à polifonia harmônica e não da teoria musical: a harmonia está latente de maneira que é possível de "realizar" a base fundamental de uma melopeia grega e de "harmonizá-la", como o fazem os músicos que reúnem os cantos populares na segunda metade do século XIX. Essa prática, que vai atingir pôr fim a harmonização do hino délfico por Gabriel Fauré em 1894 a pedido do helenista Théodore Reinach ${ }^{52}$, foi possibilitada pela confusão entre "escalas" (Tonleitern) e "modos" (Tonarten), termo habitualmente utilizado para traduzir "harmonia" no século XIX: o "modo" foi concebido no século XIX sob a forma de uma "escala" diatônica, cujo parentesco estava manifesto com as escalas modernas ${ }^{53}$. $\mathrm{O}$ que distingue em definitivo a música moderna da música antiga, é o número de "modos" e o desenvolvimento do fundamento harmônico: aos dois modos maiores correspondem sete "modos" gregos que acrescentam nuanças suplementares à alegria e à tristeza;

52 Cf. CORBIER, C. Poésie, Musique et Danse. Maurice Emmanuel et l'hellénisme, op. cit., p. 64-66.

53 CHAILLEY, J. L’imbroglio des modes, Paris: Leduc, 1960 ; POWERS, Harold S. "La modalité, une construction intellectuelle de la culture européenne", Analyse musicale. 2001/1, p. 5-15. 
os Modernos, por outro lado, acentuaram a polifonia harmônica, latente na Grécia. Nessas condições, a diferença entre música grega e música moderna aparece em Nietzsche e nos teóricos contemporâneos (Westphal, Helmholtz, Gevaert, Riemann) como uma diferença de grau e não de natureza.

Com os escritos filológicos e os fragmentos póstumos dos anos 1869-1871, nós possuímos, portanto, traços bastante claros das pesquisas que Nietzsche levou a cabo sobre harmonia e rítmica grega, e das quais $O$ nascimento da tragédia oferece uma síntese no capítulo 2.

\section{Melos e música dionisíaca}

No capítulo 2 de $O$ nascimento da tragédia, Nietzsche passa da estética geral à história da música, a qual tem nascimento na Grécia. Nietzsche não ignora o Oriente, mas ele o mantem em distância e o separa categoricamente da Grécia: a reunião do apolíneo e do dionisíaco foi realizada de maneira perfeita na poesia lírica arcaica, quando o culto de Dioniso penetra num espaço helênico onde Apolo era até agora a principal divindade. Assim, é graças à união de Apolo com Dioniso que o dionisismo na Grécia se torna fundamentalmente diferente do dionisismo bárbaro: enquanto que na Babilônia, os sacas faziam o homem regressar ao estado animal, a fusão de Apolo e de Dioniso na Grécia engendrou um "fenômeno estético" que distancia o bacante da animalidade e do puro prazer sensual. O Apolo dórico constrange o Dioniso oriental a fundir numa forma plástica os gritos de alegria e de sofrimento arrancados no êxtase ${ }^{54}$.

Daí nasce a poesia lírica, constituída pela "potência de abalo do som, a torrente homogênea do melos (der einheitliche Strom des Melos) e o modo incomparável da harmonia" (GT/NT 2, KSA 1.33).

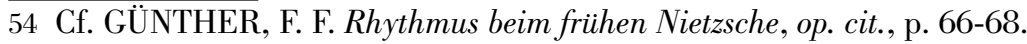

88 I Cad. Nietzsche, São Paulo, n. 34 - vol. I, p. 61-98, 2014. 
O ditirambo dionisíaco, graças ao qual o servo de Dioniso eleva todas suas faculdades simbólicas para exprimir seu entusiasmo não apenas através de gestos mas também por todos os meios (dinâmica, rítmica, harmonia), consistia portanto uma arte profundamente diferente da música oriental. Essa fusão entre apolíneo e dionisíaco é única na história da música e da poesia ocidental: o combate entre melodia e harmonia no fim do século XVI, ao qual Nietzsche faz menção, não teve lugar na Grécia, pois a harmonia e a melodia coexistiram nos gêneros da poesia lírica (poesia mélica de Safo e Anacreonte, lírica coral de Simônides, Baquílides e Píndaro) (Nachlass/FP 1869, 1 [41], KSA 7. 20).

Ainda que Nietzsche tenha eliminado a explicação histórica e teórica da noção de harmonia grega a qual ele havia exposto em Drama musical grego e em Visão dionisíaca de mundo, ele está autorizado a propor novamente a tese segundo a qual a música dionisíaca de origem oriental introduziu no mundo grego o som e a harmonia, com a dissonância harmônica que lhe é essencial - Nietzsche pôde mesmo vislumbrar a aparição de dissonâncias rítmicas na poesia lírica ${ }^{55}$. Nesse sentido, longe de ignorar a historicidade da música arcaica e de projetar nela seu entusiasmo wagneriano, o filólogo pôde se apoiar em suas próprias análises da poesia lírica dos séculos VII e VI. Além disso, ele somou um novo termo sugerindo o caráter particular do ditirambo, como um signo destinado ao filólogo sensível às conotações gregas: o "melos". É na edição corrigida de seu livro, publicado em 1874, que Nietzsche menciona o melos, ao passo que essa palavra estava ausente em $A$ visão dionisíaca de mundo e da edição de 1872. Esse termo é costumeiramente confundido com "melodia". Entretanto, Nietzsche, que

55 „Eu acredito que: o estímulo para agir com fortes dissonâncias de medidas temporais é um fruto do culto à Dionísio. Os versos logaoedicos portanto, não são esvaziados com pausas em iguais compassos" (Rhythmische Untersuchungen, KGW II, 3, p. 329). Sobre esse ponto, Cf. GÜNETHER, F. F., Rhythmus beim frühen Nietzsche, op. cit. p, 57-60 enosso artigo „Alogia et eurythmie chez Nietzsche“, Nietzsche Studien, 38, 2009, p, 13-27. 
utiliza de forma abundante em suas obras as palavras correntes de "melodia" e de "Weise", emprega muito raramente "Melos", o que deve atrair nossa atenção. Se nos atermos aos escritos filosóficos, "Melos" aparece exclusivamente nos textos consagrados à música grega antiga: no parágrafo 4 de Visão dionisíaca de mundo, no capítulo 2 de $O$ nascimento da tragédia e no parágrafo 84 da Gaia Ciência ("Origem da poesia").

Com toda evidência, é o filólogo que fala aqui: empregando em $O$ nascimento da tragédia uma noção tão conotada, Nietzsche inegavelmente sugeriu a historicidade da música dionisíaca no mesmo momento em que ele suprimia toda a referência à história da música grega. Enquanto aluno de Ritschl, ele sabia com toda certeza que a palavra grega "melos" é complexa. De fato, num artigo publicado em 1832 e republicado no primeiro volume de seus Opuscula Philologica em 1866, Ritschl havia distinguido "melos" e "ôdè": o primeiro termo designava um poema cantado que fazia parte de uma composição musical completa (isto é, como um acompanhamento instrumental), ao passo que o segundo termo designava o poema apenas cantado. Ritschl dava assim à noção de melos um lugar na poesia lírica e, por outro lado, assimilava ôdè ao "Lied" Quanto a Westphal, ele havia indicado em Metrik der Griechen que o melos correspondia ao canto e que ele era completado, na poesia lírica, pelo krousis, o acompanhamento instrumental ${ }^{57}$.

Nietzsche está interessado na noção de melos desde 1869, em seu curso sobre os poetas líricos gregos. Nas últimas páginas do curso, o filósofo distingue poesia mélica de poesia lírica. $\mathrm{O}$ adjetivo "lyrikos" por ele mesmo não denota o conjunto da poesia musical pós-homérica: derivado de "lira", esse adjetivo é uma palavra recente que terminou por se generalizar ao passo que a poesia musical é primeiramente uma poesia "mélica", isto é, uma poesia que

56 RITSCHL, F. “Ode (Volkslied) der Griechen" [1832], Opuscula Philologica, I, Leipzig: Teubner, 1866, p. 245-257 (ver sobretudo as páginas 245-249).

57 ROSSBACH, A.t; WESTPHAL, R. Metrik der Griechen, op. cit., p. 261.

90 I Cad. Nietzsche, São Paulo, n. 34 - vol. I, p. 61-98, 2014. 
une melos e krousis. Empregando o adjetivo "mélico", define-se mais corretamente a poesia grega arcaica: a poesia mélica designa a poesia acompanhada pela lira como também pelo aulo ${ }^{58}$. Depois, em 1870, em seu curso sobre Édipo rei, o próprio Nietzsche evocou a célebre definição de melos dada por Platão (República, III, 398): o melos é constituído de ritmo (rhythmos), de harmonia (harmonia) e de palavras (logos). A noção de harmonia não está explicitada nessas páginas, mas ela poderia cobrir, como nós já constatamos, as harmoniai gregas e o conceito moderno de harmonia. Nietzsche continua explicando que essa definição platônica foi retomada por Monteverdi para criar um recitativo imitando os gregos, o stilo rappresentativo firmemente condenado em $O$ Nascimento da tragédia: a invenção de Peri e de Monteverdi repousa sobre uma má interpretação a propósito da própria natureza da música grega e do melos ${ }^{59}$.

O melos foi igualmente mencionado por Aristóteles na Poética como sendo um dos elementos constitutivos da tragédia, mas Nietzsche criticou o estatuto subalterno que foi reservado a esse elemento quando comparado a intriga, resultado do desenvolvimento da leitura em detrimento da performance. Assim como para a relação entre drama e pathos, a Poética de Aristóteles testemunha um desconhecimento total da tragédia original e do ditirambo, onde o melos desempenhava o papel mais importante com o opsis realizando num espetáculo a fusão da vista e do ouvido: nas origens, não havia nem ouvinte nem espectador, mas indivíduos participando de um culto ${ }^{60}$.

Por consequência, associar o melos à música dionisíaca tem por objetivo sublinhar o papel fundamental da música na tragédia grega primitiva de Frínico e de Ésquilo, papel desconhecido por Aristóteles e rechaçado por Platão em benefício do logos e do muthos.

58 Die griechischen Lyriker, KGW, II 2, p. 170.

59 Einleitung in die Tragödie des Sophocles, KGW, II 3, p. 31.

60 Nachlass/FP 1869-1870, 3 [66], KSA 7.78. Cf. ARISTOTE, Poétique, 1450ab ; 1462a-b. 
Historicamente, o poeta mais representativo dessa poesia mélica arcaica é Arquíloco. Este é, segundo Terpandro, o primeiro poeta que utiliza melos e krousis, tal como Nietzsche leu em Westphal e no De Musica de Plutarco ${ }^{61}$. É por isso que, em $O$ Nascimento da tragédia, Arquíloco aparece como o poeta dionisíaco-apolíneo por excelência: a variedade rítmica de seus versos; o seu uso de uma instrumentação heterofônica; o seu estatuto de poeta associado ao culto apolíneo e ao culto de Demeter; sua arte realizando a síntese da subjetividade e da objetividade atestando o aparecimento de um processo estético original; a dissolução do indivíduo Arquíloco pela fusão com a música, isto é, com a Vontade, que precede a explosão em feixes de poemas líricos acalorados sob o efeito da individuação apolínea separando o poeta do Um originário ${ }^{62}$.

Além disso, Nietzsche atribui a Arquíloco o crédito de introduzir um elemento essencial para a evolução da música: a inclusão da "canção popular" (Volsklied) na arte (GT/NT 6, KSA 1.48). Ao contrário de padres-poetas organizados em casta e compondo hinos sagrados, Arquíloco utiliza as canções profanas imemoráveis cuja essência é melódica: a melodia é o elemento universal e primeiro por conta de sua origem popular e religiosa, se perdendo nos tempos pré-históricos. Todavia, a anterioridade cronológica da melodia não é contraditória em relação à primazia da harmonia: é preciso distinguir a história da música e da poesia (segundo a qual a melodia é originária) e os princípios da teoria harmônica (conforme a qual a melodia está submetida às funções tonais e ao baixo fundamental). Por consequência, Arquíloco é a antítese de Homero. A poesia daquele movimentada, tanto na forma quanto no conteúdo verbal, perturba a arquitetura fixa dos sons apolíneos e dos ritmos épicos.

61 Die griechischen Lyriker, KGW, II 2, p, 114-118, 178-180.

62 Sobre Arquíloco, nós sugerimos a leitura de nosso artigo: Subjectivité lyrique et chanson populaire: Archiloque et le genre iambique de Friedrich Schlegel à Friedrich Nietzsche“, Etudes Germaniques, 2012/2, p, 320-327. 
Tal evolução pode ser também relatada por Nietzsche em termos técnicos, como é o caso no fragmento „Kraft des Rhythmus" [Força do ritmo] dos Rhythmische Untersuchungen, [estudos rítmicos] onde se encontra a oposição entre um som reduzido a sua dimensão rítmica ("O tom é originariamente (na música citaródica \{música onde um instrumento de corda acompanha voz\}) [utilitzado] como um temporizador") e as inovações harmônicas e rítmicas ("as inovações dionisíacas em tonalidade, em rítmica (a alogia))?" $"$. Contudo nesse mesmo fragmento, Nietzsche percebe igualmente a diferença que existe entre os Gregos e os Modernos, notadamente ao que concerne a harmonia:

O Ser da música antiga é para se reconstruir; a dança mimética, a harmonia, o ritmo. Melodia, em ritmo e também na dança com os modernos. [...] É a descoberta da natureza das escalas (senso mais apurado das proporções de altura) Por que os gregos poderiam usar tons as quartas-tonais? A harmonia não havia adentrado com eles para o reino do simbolismo. Produção de simbolismo antigo ${ }^{64}$.

Assim, em 1870-1871, considerando que a harmonia moderna está instintivamente presente nas harmoniai gregos, Nietzsche descobre que surgiu um "abismo" entre os Modernos e os Gregos. O que atesta essa constatação são os quartos de tom, inexplicáveis num sistema tonal diatônico e podendo ser compreendidos apenas num sistema que escape à simbólica moderna - do mesmo modo que o ritmo grego é essencialmente diferente do ritmo moderno. $\mathrm{O}$ melos e o ritmo constituem por consequência elementos que os Modernos não percebem mais: "Falta-nos antigo gosto rítmico (o gosto para o antigo ritmo), falta-nos a melodia antiga (Melos) - como queremos ser infalíveis!", exclama Nietzsche em Zur Theorie der

63 Rhythmische Untersuchungen, KGW, II 3, p. 322.

64 Ibid.

65 Zur Theorie der quantitirenden Rhythmik, KGW, II 3, p, 268. 
quantitirenden Rhythmik depois de ter constatado a diferença de natureza entre o prazer rítmico na Grécia e nos Modernos ${ }^{66}$. Confrontado com o mesmo problema de Hanslick, o filólogo conclui que o prazer musical dos gregos se tornou incompreensível porque uma ruptura se produziu com a aparição da ópera, forma idílica, decadente e inautêntica da música grega, paralelamente ao desenvolvimento da polifonia harmônica que ocorreu no final da Idade média. No fragmento 9 [111], Nietzsche toma nota dessa evolução capital para sublinhar a perfeição da música grega:

Quando os inventores da ópera acreditaram imitar o costume grego usando o recitativo, era uma ilusão idílica. A música grega é a música mais ideal no que diz respeito a desconsiderar a entonação da palavra e ainda mais o acorde meticuloso na palavra, entre as pequenas pontas de vontade e as arseis. Ela não conhece de forma alguma a acentuação musical: seu efeito repousa sobre o ritmo temporal e sobre a melodia, $\mathrm{e}$ não sobre o ritmo das intensidades. $\mathrm{O}$ ritmo era apenas sentido, ele não se exprimia pela entonação. Eles acentuavam mais segundo o conteúdo de pensamento. Agudo e grave da nota, thesis ou arsis da cadência não tinham nada a ver com ele. Por outro lado, eles haviam desenvolvido com uma extrema finesa o senso das escalas (Tonleitern) e de ritmos temporais. Reconhece-se a prodigiosa poikilia rítmica desse povo em seu talento para a dança, enquanto que nossos esquemas rítmicos são de uma extrema pobreza (Nachlass/FP 1871, 9 [111], KSA 7.316).

Conforme as análises de Nietzsche, testemunhadas por suas pesquisas rítmicas, a rítmica grega é uma "Zeitrhythmik", uma "rítmica temporal" que está organizada segundo relações de proporções sutis e refinadas, ao contrário da rítmica moderna, patética e fundada sobre 0 acento tônico ${ }^{67}$. As "pequenas pontas da vontade"

66 Ibid.

67 Cf. CORBIER, C. "Alogia et eurythmie chez Nietzsche", op.cit.

94 I Cad. Nietzsche, São Paulo, n. 34 - vol. I, p. 61-98, 2014. 
não tinham efeito sobre a organização rítmica e musical do melos, pois as arseis "compassos" não eram acentos tônicos: compasso e pausa (arsis et thesis) remetem aos passos de dança. A poesia musical grega repousa portanto sobre o jogo das longas e das breves que formam o contexto métrico de uma estrofe lírica porque os gregos não conheciam o icto no sentido de "tempo forte". O icto se desenvolve apenas a partir do momento em que a música moderna se torna polifônica e compassada:"No ictus da nossa composição se expressa a alma de nossa melodia e harmonia"68. Nos gregos, a Vontade era traduzida de forma diferente: os afetos eram exprimidos com uma grande "finesse" na parte harmônica graças ao jogo de "escalas" e de "modos", e também na parte rítmica graças à extrema diversidade dos versos líricos. É por isso que o filólogo deve proceder a uma "reconstrução" completa da essência da música grega.

Em seus fragmentos, Nietzsche levantou, portanto, o problema da historicidade da música grega: o melos repousava sobre uma rítmica e uma "harmônica" da qual os Modernos perderam a chave que Nietzsche espera revelar no início dos anos 1870. Como, nessas condições, pode-se afirmar ao mesmo tempo o parentesco da música grega e sua alteridade, tal como ela é revelada pelos traços de uma rítmica e de um melos fundamentalmente diferentes? Estudando a música grega historicamente e filosoficamente, Nietzsche chega a uma aporia: de um ponto de vista teórico, as obras de Westphal e de Helmholtz provam que os fundamentos da música grega e da música moderna são idênticos. Por outro lado, a filologia revela a historicidade do gosto não apenas no domínio rítmico, mas também no domínio harmônico: a música dionisíaca não tinha nada em comum com a música moderna.

Se em $O$ nascimento da tragédia Nietzsche gratifica Wagner de ter reatado com a música dionisíaca primitiva - interrompida por Eurípedes e Sócrates satisfazendo a musicalização integral das

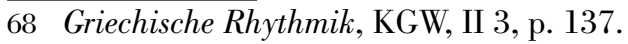


palavras sobre o modelo do melos ditirâmbico -, ele voltará alguns anos mais tarde a esse problema mudando totalmente de perspectiva. No parágrafo 171 de Opiniões e Máximas, abandonando a metafísica em nome da ciência histórica, ele proclamará doravante a historicidade da música. Todavia, se a associação do dionisíaco e da harmonia na parte histórica de $O$ nascimento da tragédia pode nos surpreender hoje em dia, não havia nada de propriamente escandaloso para os historiadores da música dos anos 1860-1870. A dificuldade de interpretação surge do estilo elíptico adotado por Nietzsche, que "aliviou" consideravelmente os fundamentos de sua tese em $O$ nascimento da tragédia. Mais nada deixa entrever a amplitude de suas pesquisas realizada a partir de 1868 sobre o tema técnico e filológico por excelência que é o estudo da música grega antiga. $\mathrm{O}$ capítulo 2 ilustra admiravelmente essa reticência frente à administração da prova que Nietzsche louva em 1886 em sua Tentativa de autocrítica (GT/NT 3, KSA 1.14): mesmo se uma leitura filológica comporta o risco de trair a ambição estética do helenista wagneriano, apenas o estudo do contexto, que os comentários recentes de $O$ nascimento da tragédia analisaram por vários aspectos, pode fazer justiça à intensa reflexão de Nietzsche sobre a música grega. Tal estudo permite assim, sem dúvida alguma, melhor compreender porque a aparição da harmonia está intimamente ligada à irrupção da música dionisíaca na Grécia arcaica.

\footnotetext{
Abstract: The present article tries to show that aesthetics theses that appear in The Birth of Tragedy are not the result of simple Nietzsche's subjective projection on Greek art. This is because, underlying the argumentation of The Birth of Tragedy, there would be a vast historiographical reason whose traces can be found in philological texts that precede Nietzsche's first philosophical work. Keeping this in mind, our article will conduct an investigation in Nietzsche's texts to try to prove that the accusation of "subjective projection" can not be sustained. During the examination, we will try to show that, for example, Nietzsche's
} 
understanding of the link between historical appearance of harmony and the Greek Dionysism is closely linked to the positions that appear in their philological studies of the years 1860-1871. Positions that were derived and were legitimized by historicals researches from the nineteenth century.

Keywords: The Birth of Tragedy - Dionysian - harmony - music - melody - Greek culture

\section{referências bibliográficas}

1. BARKER, A. Greek Musical Writings, II, Cambridge, Cambridge University Press, 1989 ,

2. BÉLIS, A. Aristoxène de Tarente et Aristote: le Traité d'Harmonique. Paris: Klincksieck, 1986. p, 88-115.

3. BÖKH, A. De Metris Pindari. In : Pindari Opera quae supersunt, I, Leipzig: Weigel, p, 253-257.

4. CHAILLEY, J. Traité historique d'analyse harmonique. Paris: Leduc, 1977. p, 34-37.

5. L'imbroglio des modes. Paris: Leduc, 1960

6. CORBIER, C. Poésie, musique et danse. Maurice Emmanuel et l'hellénisme. Paris: Classiques Garnier, 2010, p, 44-60.

7. . Subjectivité lyrique et chanson populaire: Archiloque et le genre iambique de Friedrich Schlegel à Friedrich Nietzsche“, Etudes Germaniques, 2012/2, p, $320-327$.

8. DUFOUR, E. L'esthétique musicale de Nietzsche. Lille: Presses du Septentrion. 2005.

9. GRAND-CLÉMENT, A. «Couleur et esthétique classique au XIX ${ }^{\mathrm{e}}$ siècle : l'art grec antique pouvait-il être polychrome ?» In Ithaca. Quaderns Catalans de Cultura Clàssica, 21, 2005. p, 139-160.

10. GÜNTHER, F. F. Rhythmus beim frühen Nietzsche. Berlin: De Gruyter, 2008.

11. HANSLICK, E. Du Beau musical. Trad. Alexandre Lissner, Paris: Hermann, 2012. p, 169-170.

12. HELMHOLTZ, H. Théorie physiologique de la musique. Trad. G. Guéroult. Paris: Victor Masson, 1868.

13. JOCKEY, P, Le mythe de la Grèce blanche. Paris: Belin, 2012.

14. LANDERER, C.; SCHUSTER, M. Nietzsches Vorstudien zur Geburt der Tragödie in ihrer Beziehung zur Musikästhetik Eduard Hanslicks“, Nietzsche Studien, 31, 2002, p, 119-120.

Cad. Nietzsche, São Paulo, n. 34 - vol. I, p. 61-98, 2014. | 97 
Corbier, C.

15. LIÉBERT, G. Nietzsche et la musique. Paris: PUF-Quadrige, 1995.

16. NIETZSCHE, F. Sämtliche Werke. Kritische Studienausgabe (KSA). Organizada por Giorgio Colli e Mazzimo Montinari. Berlim: Walter de Gruyter \& Co., 1999, 15 v. 17. Kritische Gesamtausgabe: Werke, editada por Giorgio Colli e Mazzino Montinari. Berlin: Walter de Gruyter \& Co, 1967-2001. 36v.

18. Correspondance. Paris: Gallimard, 1986.

19. POWERS, H. S. "La modalité, une construction intellectuelle de la culture européenne", Analyse musicale. 2001/1, p, 5-15

20. REIBNITZ, B. Ein Kommentar zu Friedrich Nietzsche, "Die Geburt der Tragödie aus dem Geiste der Musik» (Kap, 1-12), Weimar: Verlag J. B. Metzler Stuttgart, 1992.

21. RITSCHL, F., „Ode (Volkslied) der Griechen“ [1832], Opuscula Philologica, I, Leipzig: Teubner, 1866. p, 245-257.

22. ROSSBACH, A.; WESTPHAL, Rudolf. Metrik der Griechen im Vereine mit dem übrigen musischen Künsten. Leipzig: Teubner, 1867. p, 260.

23. ROSSEAU, J.-J. Euvres complètes. V. Paris: La Pléiade, 1995.

24. SCHMIDT, J. Nietzsche-Kommentar. Die Geburt der Tragödie, Berlin-New-York: De Gruyter, 2012,

25. SILK, S.; STERN, J. P. Nietzsche on tragedy, Cambridge: Cambridge University Press, 1981.

26. WAGNER, R. Beethoven. trad. Jean-Louis Crémieux-Brilhac. Paris: Gallimard, 1970.

27. WESTPHAL, R. Geschichte der alten und mittelalterlichen Musik. Breslau: Leuckart, 1865.

Artigo recebido em 15/11/2013.

Artigo aceito para publicação em 20/01/2014.

98 I Cad. Nietzsche, São Paulo, n. 34-vol. I, p. 61-98, 2014. 